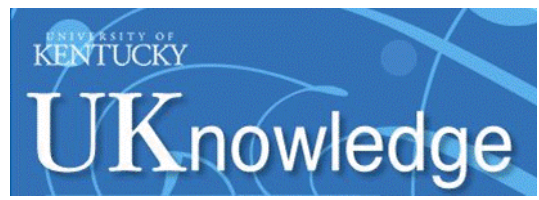

University of Kentucky

UKnowledge

Power and Energy Institute of Kentucky Faculty Publications

\title{
Axial-Flux PM Synchronous Machines with Air-Gap Profiling and Very High Ratio of Spoke Rotor Poles to Stator Concentrated Coils
}

\author{
Vandana Rallabandi \\ University of Kentucky, vandana.rallabandi@uky.edu \\ Narges Taran \\ University of Kentucky, narges.taran@uky.edu \\ Dan M. Ionel \\ University of Kentucky, dan.ionel@uky.edu \\ Ion G. Boldea \\ Universitatea Politehnica Timisoaraand Romanian Academy, Romania
}

Follow this and additional works at: https://uknowledge.uky.edu/peik_facpub

Part of the Power and Energy Commons

Right click to open a feedback form in a new tab to let us know how this document benefits you.

\section{Repository Citation}

Rallabandi, Vandana; Taran, Narges; Ionel, Dan M.; and Boldea, Ion G., "Axial-Flux PM Synchronous Machines with Air-Gap Profiling and Very High Ratio of Spoke Rotor Poles to Stator Concentrated Coils" (2017). Power and Energy Institute of Kentucky Faculty Publications. 48.

https://uknowledge.uky.edu/peik_facpub/48

This Conference Proceeding is brought to you for free and open access by the Power and Energy Institute of Kentucky at UKnowledge. It has been accepted for inclusion in Power and Energy Institute of Kentucky Faculty Publications by an authorized administrator of UKnowledge. For more information, please contact UKnowledge@lsv.uky.edu. 


\title{
Axial-Flux PM Synchronous Machines with Air-Gap Profiling and Very High Ratio of Spoke Rotor Poles to Stator Concentrated Coils
}

\author{
Digital Object Identifier (DOI) \\ https://doi.org/10.1109/IEMDC.2017.8002371
}

\section{Notes/Citation Information}

Published in 2017 IEEE International Electric Machines and Drives Conference (IEMDC).

(C) 2017 IEEE Copyright Notice. "Personal use of this material is permitted. Permission from IEEE must be obtained for all other uses, in any current or future media, including reprinting/republishing this material for advertising or promotional purposes, creating new collective works, for resale or redistribution to servers or lists, or reuse of any copyrighted component of this work in other works."

The document available for download is the authors' manuscript version that is accepted for publication. The final published version is copyrighted by IEEE and available as: V. Rallabandi, N. Taran, D. M. Ionel and I. G. Boldea, "Axial-flux PM synchronous machines with air-gap profiling and very high ratio of spoke rotor poles to stator concentrated coils," 2017 IEEE International Electric Machines and Drives Conference (IEMDC), Miami, FL, 2017, pp. 1-7. doi: 10.1109/IEMDC.2017.8002371

This conference proceeding is available at UKnowledge: https://uknowledge.uky.edu/peik_facpub/48 


\section{Axial-flux PM Synchronous Machines with Air-gap Profiling and Very High Ratio of Spoke Rotor Poles to Stator Concentrated Coils}

\author{
Vandana Rallabandi, Narges Taran and Dan M. Ionel, Fellow, IEEE \\ Department of Electrical and Computer Engineering \\ University of Kentucky, Lexington, KY, USA \\ vandana.rallabandi@uky.edu,narges.taran@uky.edu,dan.ionel@uky.edu
}

\author{
Ion G. Boldea, Life Fellow, IEEE \\ Universitatea Politehnica Timisoara, \\ Romania \\ ion.boldea@upt.ro
}

\begin{abstract}
Permanent magnet machines including a magnetic gearing effect are attractive for low-speed high-torque applications. This paper proposes a dual-stator axial-flux machine topology with a high ratio for the number of rotor poles to concentrated stator coils. The stator consists of a relatively small number of teeth, with each tooth including multiple smaller/auxiliary teeth. The rotor employs spoke-type permanent magnets, which result in high flux concentration, thereby further improving the torque density. The paper discusses the principle of operation of the proposed machine topology. Finite element results on example designs with 6 stator teeth, each having 2 and 3 auxiliary teeth, and with 20,32 , and 34 rotor poles are presented, respectively. Other feasible slot-pole combinations are also identified.
\end{abstract}

Index Terms-Permanent magnet machines, axial flux, Vernier electric machines, spoke permanent magnets, special electric motors, high-torque low-speed machines, electromagnetic FEA.

\section{INTRODUCTION}

Permanent magnet (PM) machines with an integrated magnetic gearing effect are useful for low-speed direct-drive applications because of their potential for very high torque density. Such PM machine topolgies, often referred to as derivations of the Vernier-type concept, have been proposed over the years, going back to 1990 [1] and with more recent researches published, for example, in [2]-[8]. Due to the high magnetic leakage and relatively large equivalent air-gap, the power factor is inherently low in these types of electrical machines and in order to improve performance dual stator arrangements have been proposed, e.g. [3], [4], [9].

The work described in this paper brings further contributions to the topic by proposing the use, in such a single-rotor doublestator arrangement, of concentrated coils wound around a set of main stator teeth with profiled tips creating additional smaller teeth and modulating the air-gap surface in order to enhance a magnetic gearing effect. A "spoke" PM rotor is employed for magnetic flux concentration and the combination of central rotor arrangement with special design provisions for

The support of University of Kentucky, the L. Stanley Pigman endowment, and ANSYS, Inc. is gratefully acknowledged. the placement and winding of the two stators ensures minimum flux leakage leading to very high specific magnetic loading.

The studies reported in this paper indicate that the proposed topology may be suitable especially for for low-speed directdrive applications. Nevertheless, with the recent developments of power electronics and the availability of wide band gap semiconductor devices, which have the ability to switch at very high frequencies, the use of this high polarity machine may be extended also to higher speed applications [10].

In the following section, possible combinations of large and small/auxiliary teeth and rotor poles are investigated for threephase windings, especially with low number of concentrated coils, e.g. 6, 9 and 12. The principle of operation for this machine topology is explained and illustrated for a design with 6 coils and main stator teeth, each including 2 or 3 auxiliary teeth. The third section of the paper covers main design considerations and associated finite element analysis (FEA) for machines with 20,32 , and 34 rotor poles. A technique for improving performance by circumferentially shifting the two stators with respect to each other and a comparative design study are described in the fourth section before drawing conclusions.

\section{Proposed High Polarity Motor Topology}

The proposed machine topology, which employs stator coils concentrated around special main teeth that have notches in the tips creating auxiliary teeth and a high polarity PM rotor, is exemplified in a single-rotor dual-stator axial flux arrangement in Fig.1. Such machines can be designed with different numbers of stator teeth and rotor poles as illustrated in Fig.2.

The operating principle of these special motors has similarities with Vernier type machines and magnetic gears, and can be explained though the fact that the armature MMF, which has a number of poles not equal to that of the rotor, is modulated by the main, auxiliary stator teeth, and slots such that a component of flux density corresponding to the rotor poles is created in the air-gap. The relation between the 


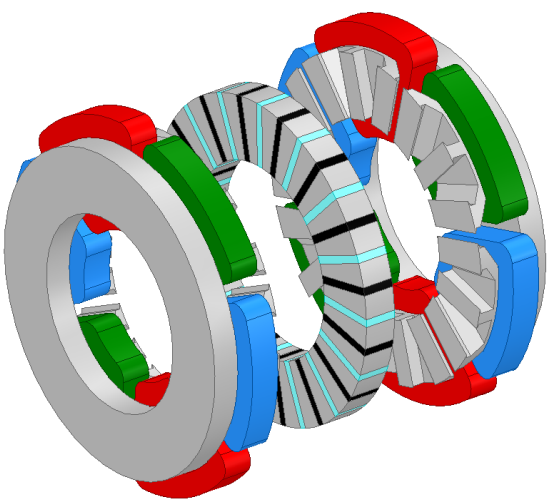

(a)

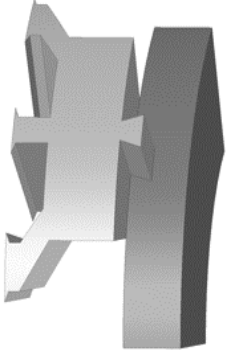

(b)
Figure 1. High polarity axial flux machine concept with rotor PMs in a spoketype arrangement and multiple stator teeth, including a modulated profile towards the air-gap. Flux concentration and modulation is achieved by the dual action of the PMs and stator teeth. The special stator teeth shape allows the use of a relatively small number of coils, which may be pre-wound. High slot fill factors could be achieved together with the possible use of compressed aluminum conductor technology.

number of rotor poles, main and auxiliary stator teeth and armature poles is established as:

$$
P_{r}=2 \times T_{m s} \times t_{s t}-P_{a},
$$

where, $P_{r}$ is the number of rotor poles; $T_{m s}$, the number of main stator teeth; $t_{s t}$, the number of auxiliary stator teeth and $P_{a}$, the number of armature poles.

The operating principle of the proposed topology is exemplified for the afore mentioned 6/32 machine design. The following simplified analysis neglects the saliency introduced by the spoke PM rotor, which might be significant, depending on different factors such as the number of poles, and the ratio of PM pole width to the pole pitch. Furthermore, the analysis also assumes that the widths of the main and auxiliary stator slots are the same.

Considering, for example, a machine with 6 main stator teeth, and 3 auxiliary teeth per main stator tooth, wound for 4 poles, the number of rotor poles required is 32 (Fig.2b). For simplicity such a configuration will be referred to in the following as a 6/32 design. Examples of other feasible stator teeth and rotor pole combinations, together with their fundamental winding factors, are listed in Table I. In a variation of this machine topology, if the armature is wound for 2 poles, the number of rotor poles required is 34 as per (1).

The 6/32 machine has the same winding configuration as a 6-slot(teeth) 4-pole PM synchronous machine, the armature reaction MMF of which (Fig. 3a) may be expressed in the form of a Fourier Series over one mechanical cycle of $360^{\circ}$ as follows:

$$
\begin{array}{r}
M M F=\frac{9}{4 \nu \pi} \sum_{\nu=2,10,16,22 . .}^{\infty} \cos \left(\nu \theta+\frac{\pi}{3}\right)- \\
\frac{9}{4 \nu \pi} \sum_{\nu=4,8,14,20 . .}^{\infty} \cos \left(\nu \theta-\frac{\pi}{3}\right),
\end{array}
$$

Table I

FEASIBLE LARGE STATOR TEETH, SMALL STATOR TEETH, AND ROTOR POLE COMBINATIONS

\begin{tabular}{ccccc}
\hline $\begin{array}{c}\text { Large Stator } \\
\text { Teeth }\end{array}$ & $\begin{array}{c}\text { Armature } \\
\text { Poles }\end{array}$ & $\begin{array}{c}\text { Small Stator } \\
\text { Teeth }\end{array}$ & $\begin{array}{c}\text { Rotor } \\
\text { Poles }\end{array}$ & $\begin{array}{c}\text { Winding } \\
\text { Factor }\end{array}$ \\
\hline 6 & 2 & 2 & 22 & 0.500 \\
& & 3 & 34 & 0.500 \\
& & 4 & 46 & 0.500 \\
\hline 6 & 4 & 2 & 20 & 0.866 \\
& & 3 & 32 & 0.866 \\
& & 4 & 44 & 0.866 \\
\hline 9 & 6 & 2 & 30 & 0.866 \\
& & 3 & 48 & 0.866 \\
& & 4 & 66 & 0.866 \\
\hline 12 & 8 & 2 & 40 & 0.866 \\
& & 3 & 64 & 0.866 \\
& & 4 & 88 & 0.866 \\
\hline
\end{tabular}

and thus the MMF contains not only a 4 pole $(\nu=2)$ component, but also $8,16,20$, and 28 pole components.

The permeance, $P_{m}$, due to all the slot openings and teeth on the air-gap surface (Fig. 3b) can be expressed by neglecting the higher order components as:

$$
P_{m}=h_{o}+h_{1} \cos 18 \theta,
$$

where $h_{o}$ is the DC component of the permeance, and $h_{1}$ is its fundamental component corresponding to the total number of slot openings, i.e. main slots and "dummy" slots/notches on the stator teeth i.e. $T_{m s} \times t_{s t}$ ).

The airgap flux due to the armature reaction is the product of the previous two terms,

$$
\begin{aligned}
B_{g}= & P \frac{9}{8 \pi}\left[\cos \left(2 \theta+\frac{\pi}{3}\right)-\cos \left(4 \theta-\frac{\pi}{3}\right)+\cos \left(10 \theta+\frac{\pi}{3}\right)\right. \\
& \left.-\cos \left(8 \theta-\frac{\pi}{3}\right)+\cos \left(16 \theta+\frac{\pi}{3}\right)-\cos \left(14 \theta+\frac{\pi}{3}\right) \ldots\right] .
\end{aligned}
$$

The 32 pole component of this air-gap flux density (see order $\nu=16$ in Fig. 3d) is substantial and interacts with the 32 pole PM rotor field in order to produce a net synchronous torque.

Furthermore, because the permeance has, in addition to the high-order harmonic, a DC component, all the MMF harmonics are also present in the air-gap flux density, i.e. 4, 8, 16, 20, 28, and others, as illustrated in Fig. 3d. Therefore, the 32 pole component already present in the armature MMF is further enhanced by the interaction of the 4 pole $(\nu=2)$ component of the armature MMF with the fundamental component of the permeance, which has a mechanical harmonic order of 18 .

The non-torque producing components create loss in the rotor as well as torque pulsations, and can be reduced, in principle, by appropriate electromagnetic design. 


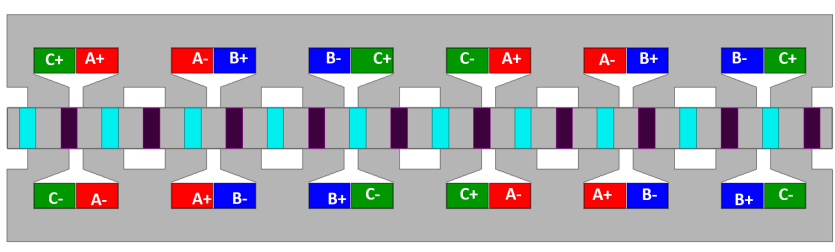

(a)

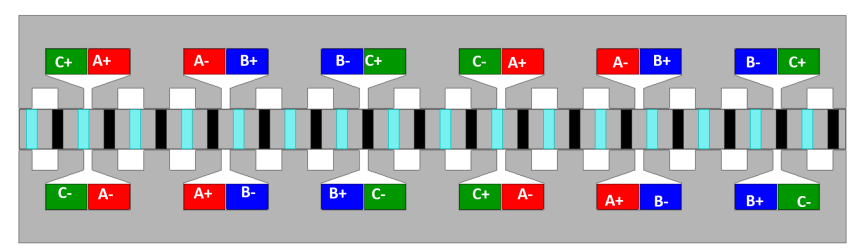

(b)

Figure 2. Developed (linearly unrolled) view of the proposed axial flux PM machine with (a) two and (b) three small (auxiliary) stator teeth, created per each main tooth by tip notches. For both topologies, the connections of the concentrated coils are made such as to produce a four pole armature flux. Different number of poles, 20 and 32, respectively, are employed in the rotor in order to correlate with the stator topology and maximize torque production as exemplified in Table I. The designs are illustrated in "spoke" PM rotor arrangements, but other rotor topologies are also possible.

\section{Finite ELEMENT ANALYSis (FEA) AND DESIGN CONSIDERATIONS}

Two-dimensional finite element analysis (FEA) was employed for modeling the proposed AFPM machine in an unrolled plane at the average machine diameter. The outer and the inner diameters of the stator core are $250 \mathrm{~mm}$ and $150 \mathrm{~mm}$, respectively. Studies were performed at an operational speed of $300 \mathrm{rpm}$.

The performance of three different machine topologies, i.e. a $6 / 20$ machine with 2 auxiliary teeth per main stator tooth, a $6 / 32$ machine with 3 auxiliary teeth per main tooth; and of a 6/34 machine, with 3 auxiliary teeth per main tooth was comparatively studied. All three machines have the same dimensions and the same copper losses. Results are summarized in Table II.

It is noted that the $6 / 32$ machine performs significantly better in terms of output power, efficiency, and torque ripple. trends are in line with expectations as the torque density increases with the number of auxiliary stator teeth. Nevertheless, the PM fringing flux also increases with the number of auxiliary stator teeth, meaning that there is an upper limit for the number of auxiliary stator teeth that may be profitably employed.

It is also observed that both the $6 / 32$ and the $6 / 20$ machine significantly outperform the $6 / 34$ machine, in terms of output power and "goodness", which is defined as the ratio between the output torque and the square root of power losses. Superior performance may be in part attributed to the higher winding factor of the former two machines. A more in depth systematic study is required as, for example, the $6 / 34$ machine has a pole ratio of 17 , while the $6 / 20$ and $6 / 32$ have a 5 and 8 ratio, respectively, and a higher pole ratio may lead to higher leakage [11], while, on the other hand, the flux concentration for the same diameter increases with the number of poles for a "spoke" rotor.

All the machines were designed such that the width of each auxiliary stator tooth equals the rotor pole pitch. This also equals the widths of the auxiliary slots. As a result the width of the main slot opening, $w_{\text {so }}$, for the example 6/32 machine has a fixed value of

$$
w_{\text {so }}=\frac{32 \tau-6 \times 5 \tau}{6}=1 / 3 \tau,
$$

where $\tau$ is the PM rotor pole pitch.

In this case, the pole pitch at the inner rotor diameter is approximately $15 \mathrm{~mm}$ resulting in a stator slot opening of about $5 \mathrm{~mm}$, which is a relatively small value being given the overall dimensions of the considered motor design. This could require special manufacturing techniques, for instance, the stator teeth may be pre-wound and inserted into the stator back iron as seen in Fig. 1b. In this regard, the 6/34 machine that has a width of the slot opening of $2 / 3 \tau$, which for the inner diameter of the studied motor design comes out to be around $9 \mathrm{~mm}$, has an advantage. It should be noted that although designs with the widths of both auxiliary stator teeth and slots set equal to the rotor pole pitch were considered in this study, it is expected that varying these widths may have a direct effect on the air-gap permeance and hence, the torque. These design issues are currently subjects for further studies.

This topology also presents other manufacturing challenges specific to spoke PM rotors, which may comprise discrete solid or laminated pole pieces bolted together, and a non magnetic hub in between the shaft and permanent magnets. Another possible construction consists of individual rotor laminations with intricate thin bridges towards the shaft and, possibly, towards the airgap as well.

In case of the stator, an alternative construction may be employed, using open slots. A specially fabricated toothed structure may be subsequently placed on the surface of the stator core facing the airgap. This approach might present dual advantages in terms of manufacturability, as well as for decoupling the selection of the number of modulator teeth from the number of stator teeth, in contrast to the current construction wherein the number of modulator teeth is forced to be an integral multiple of the number of stator teeth.

As part of the study, an alternative machine configuration comprising two rotors and a stator with a set of concentrated coreless coils "sandwiched" between stationary auxiliary/modulating teeth, i.e blocks of ferromagnetic steel is considered. The use of the ferromagnetic modulation would allow in this topology the use of a relatively large number of PM poles, for a small number of concentrated stator coils. As an example, a 6 coil machine with 32 poles and 18 modulating teeth was examined. 


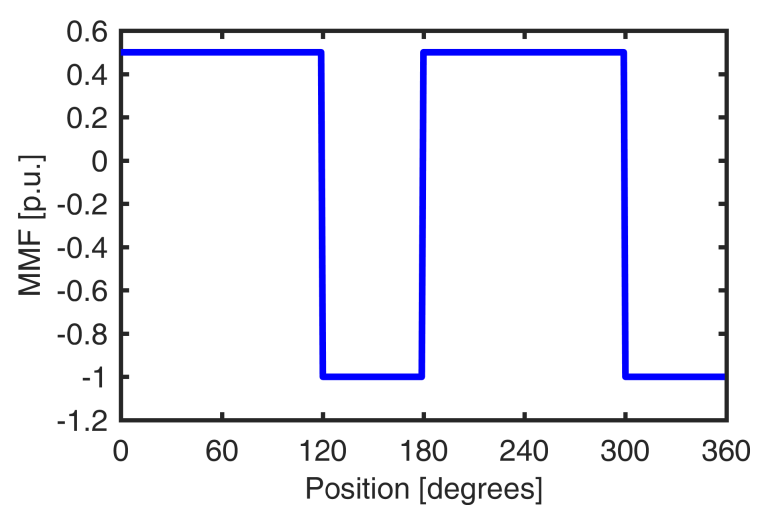

(a)

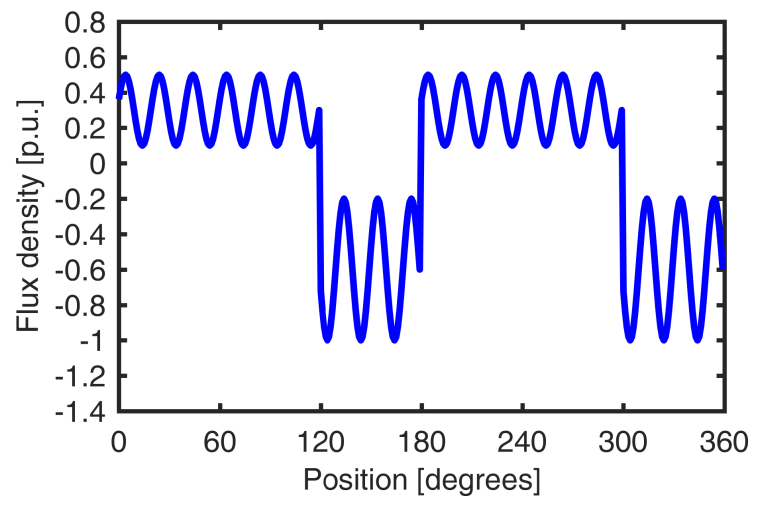

(c)

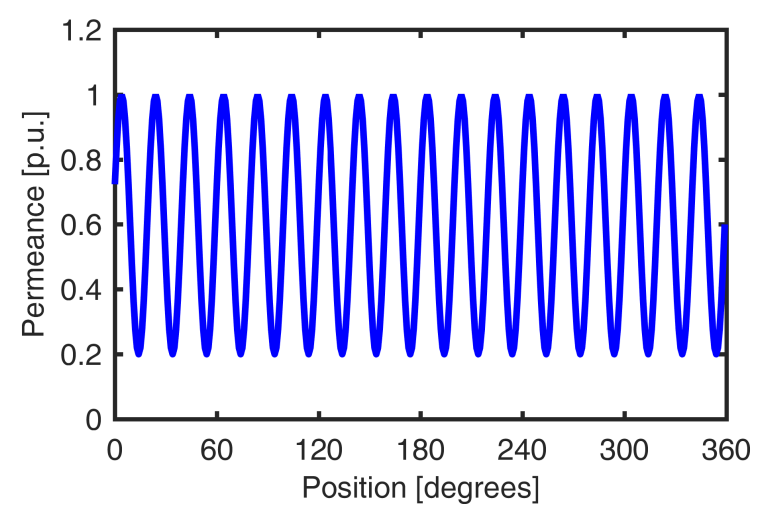

(b)

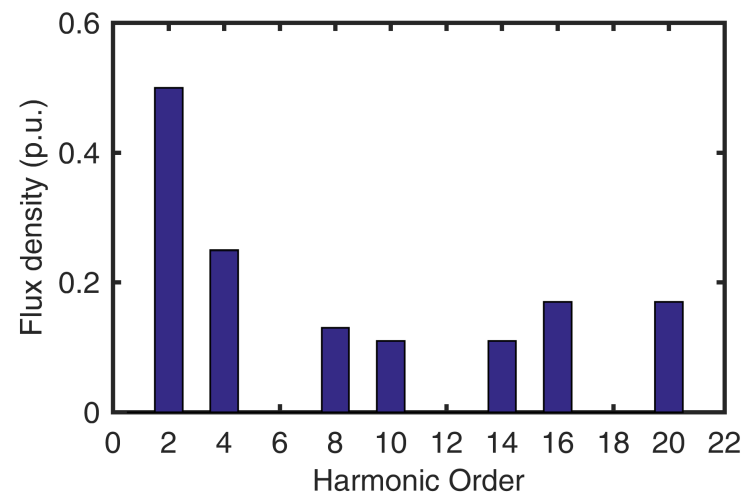

(d)

Figure 3. Analytically estimated MMF, permeance, and flux density in the air-gap an example machine with 6 large stator teeth, each with 3 small (auxiliary) teeth, and 32 rotor poles. The 4 pole armature reaction MMF is modulated by the stator teeth enhancing the 32 pole component of armature MMF. This component interacts with the rotor field in order to produce the main synchronous torque.
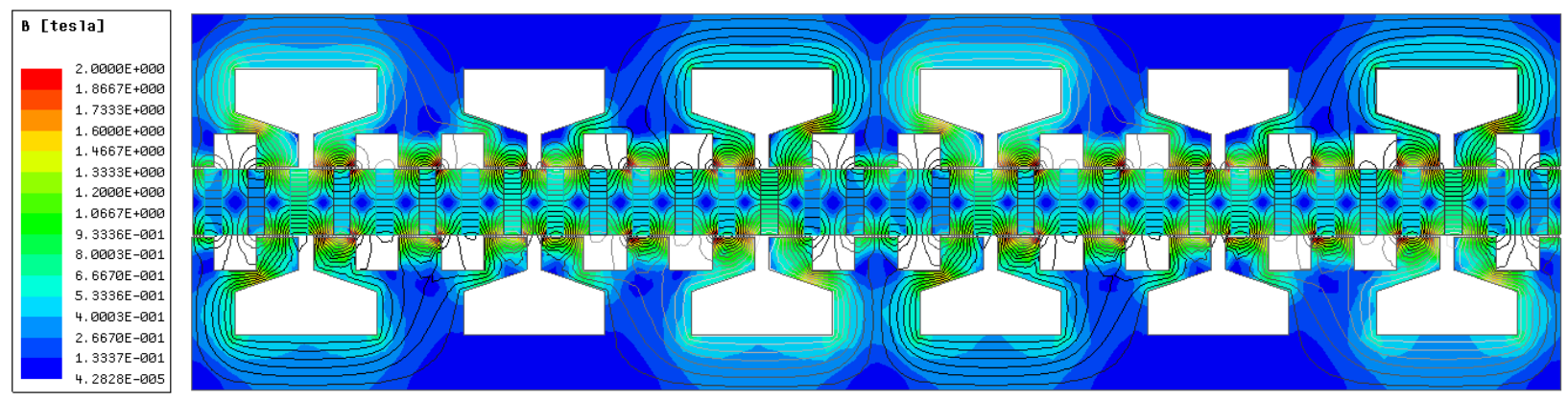

Figure 4. Open circuit flux lines obtained from 2D FEA, illustrating the high leakage of the PM flux affecting the air-gap flux and yielding a reduced flux density in the stator back iron.

Table II

PERFORMANCE COMPARISON OF THE PROPOSED MACHINES AT A RATED SPEED OF 300 RPM. ALL THE MACHINES HAVE THE SAME MAIN DIMENSIONS AND COPPER LOSS. IN ALL CASES, THE TWO STATORS ARE AXIALLY AND CIRCUMFERENTIALLY ALIGNED WITH RESPECT TO THE CENTRAL ROTOR.

\begin{tabular}{ccccccccc}
\hline $\begin{array}{c}\text { Coils/Rotor } \\
\text { Poles }\end{array}$ & $\begin{array}{c}k_{t} \\
(\mathrm{Nm} / \mathrm{A})\end{array}$ & $\begin{array}{c}\text { Output } \\
(\mathrm{kW})\end{array}$ & $\begin{array}{c}\text { Core Loss } \\
\text { Loss }(\mathrm{W})\end{array}$ & $\begin{array}{c}\text { Copper } \\
\text { Loss }(\mathrm{W})\end{array}$ & $\begin{array}{c}\text { Goodness } \\
(\mathrm{Nm} / \sqrt{W})\end{array}$ & $\begin{array}{c}\text { Torque } \\
\text { ripple }(\%)\end{array}$ & $\begin{array}{c}\text { Power } \\
\text { factor }\end{array}$ & $\begin{array}{c}\text { Electrical } \\
\text { efficiency }(\%)\end{array}$ \\
\hline $6 / 20$ & 7.20 & 3.39 & 90 & 318 & 5.34 & 45 & 0.75 & 89.3 \\
$6 / 32$ & 8.00 & 3.77 & 120 & 318 & 5.75 & 33 & 0.70 & 89.9 \\
$6 / 34$ & 4.58 & 2.16 & 84 & 318 & 3.43 & 81 & 0.81 & 84.3 \\
\hline
\end{tabular}




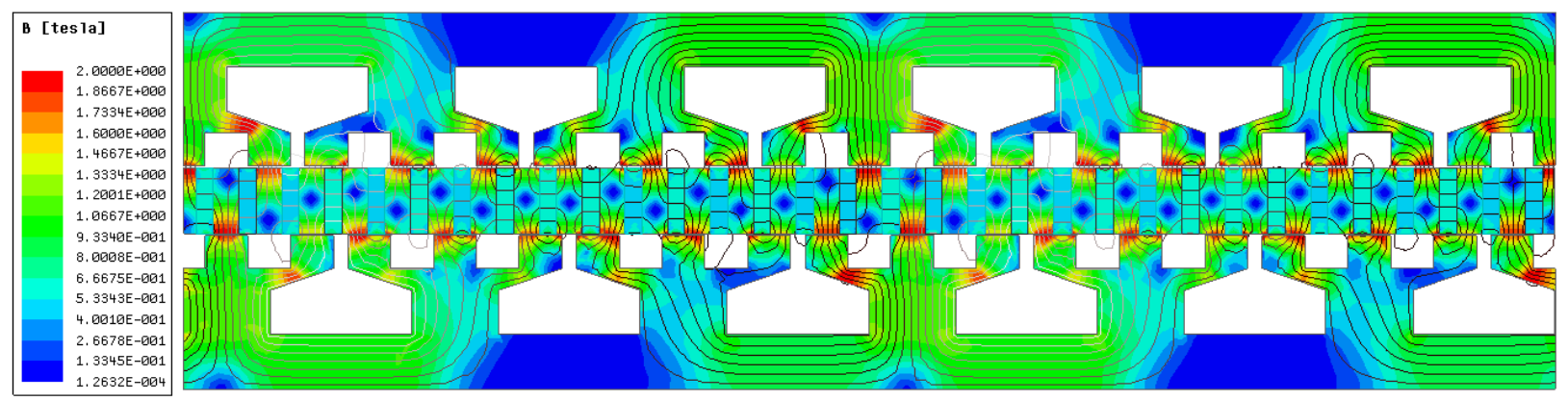

Figure 5. Open circuit flux lines with the two stators circumferentially shifted by one rotor pole pitch with respect to each other. The magnetic flux leakage is greatly reduced as compared with Fig. 4. The utilization of the PMs is increased with most of them actively contributing to the flux production.

Table III

PERFORMANCE COMPARISON OF THE PROPOSED MACHINES AT A RATED SPEED OF 300 RPM. ALL THE MACHINES HAVE THE SAME MAIN DIMENSIONS AND COPPER LOSS. IN ALL CASES, THE TWO STATORS ARE CIRCUMFERENTIALLY SHIFTED WITH RESPECT TO EACH OTHER BY ONE ROTOR POLE PITCH OR $180^{\circ}$ ELECTRICAL

\begin{tabular}{ccccccccc}
\hline $\begin{array}{c}\text { Coils/Rotor } \\
\text { Poles }\end{array}$ & $\begin{array}{c}k_{t} \\
(\mathrm{Nm} / \mathrm{A})\end{array}$ & $\begin{array}{c}\text { Output } \\
(\mathrm{kW})\end{array}$ & $\begin{array}{c}\text { Core Loss } \\
\text { Loss }(\mathrm{W})\end{array}$ & $\begin{array}{c}\text { Copper } \\
\text { Loss }(\mathrm{W})\end{array}$ & $\begin{array}{c}\text { Goodness } \\
(\mathrm{Nm} / \sqrt{W})\end{array}$ & $\begin{array}{c}\text { Torque } \\
\text { ripple (\%) }\end{array}$ & $\begin{array}{c}\text { Power } \\
\text { factor }\end{array}$ & $\begin{array}{c}\text { Electrical } \\
\text { efficiency (\%) }\end{array}$ \\
\hline $6 / 20$ & 11.56 & 5.47 & 145 & 318 & 8.05 & 27 & 0.83 & 92.2 \\
$6 / 32$ & 17.97 & 8.47 & 320 & 318 & 8.47 & 12 & 0.80 & 92.9 \\
$6 / 34$ & 15.85 & 7.47 & 396 & 318 & 8.90 & 20 & 0.89 & 91.3 \\
\hline
\end{tabular}

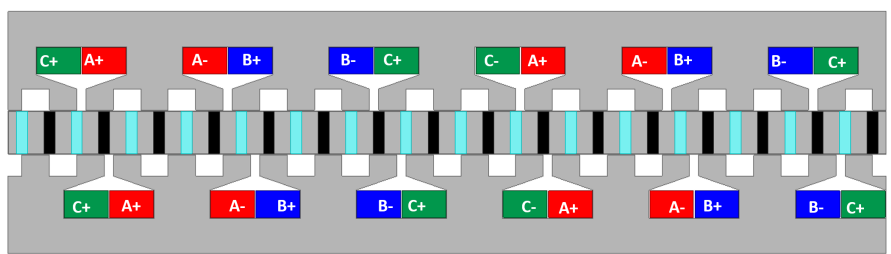

Figure 6. Developed view of the proposed axial flux PM machine with the two stators circumferentially shifted by one rotor pole pitch with respect to each other. The coil connections in the stators need to be modified as compared with Fig. 2b.

\section{Performance Improvement b y Relatively SHIFTING THE STATORS}

In order to improve the performance of Vernier-type machines, a relative circumferential shift of the stators by one rotor pole pitch has been previously proposed, e.g [1], [3], [4]. For the topology proposed in the current paper, such a procedure aims to lower the magnetic flux leakage and increase the number of magnets actively participating in the flux production at any rotor position and operation instance with an ultimate target of improving performance, including power factor.

Hence, for each of the topologies previously introduced, the effect of shifting the rotors is studied. When the two stators are shifted with respect to each other by one rotor pole pitch, the stator coil connections need to be reversed (Fig. 6). The resultant magnetic field, which is illustrated in Fig. 5 for the example $6 / 32$ machine, has substantially reduced flux leakage that is evidenced by the higher flux density in the stator back iron. Closer observation of the example field pattern shows that most of the PMs are active.

The open circuit emf and torque with and without shifting are shown in Fig.7. It is seen that the open circuit EMF more than doubles, as does the instantaneous torque. In both cases, with and without shifting, the stator copper losses are equal.

The effect of shifting the stators in the other topologies was also explored, and significant performance improvements were observed. Similarly to the $6 / 32$ machine, the open circuit voltage and torque are substantially enhanced (Fig. 8 and 9). The results included in Table III indicate that for the three designs studied, the core loss also increase upon circumferentially shifting the two stators, due to higher flux density in different parts of the magnetic circuit.

An interesting point to be noted is that the shifting of stators improves the performance of the designs with a higher number of poles considerably, to a much larger extent than for the example $6 / 20$ machine. This could be explained by considering that the magnetic fringing and leakage is expected to increase with the number of poles. Hence, the $6 / 20$ machine has the least leakage among the studied examples and the 6/34 design has the highest. Because the relative shifting of the two stators increases the number of useful magnets, thereby reducing leakage, the improvement achieved by shifting in the former configuration is not that significant.

The shifting of the stators for the designs considered improves the power factor, goodness and the power output achievable from the same frame size (Table III). Furthermore, the peak-to-peak torque ripple remains almost the same upon shifting, and, as average torque increases, the percentage ripple 


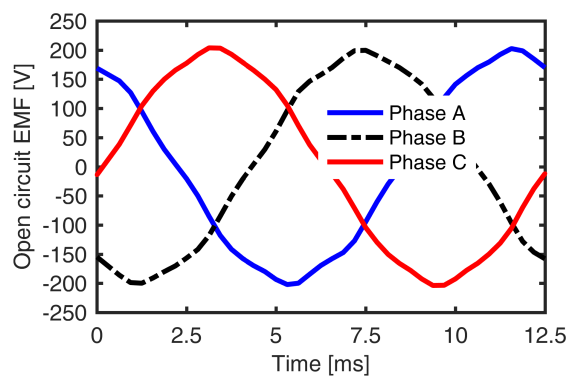

(a)

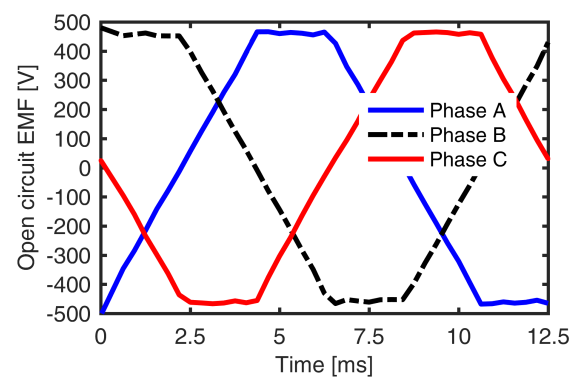

(b)

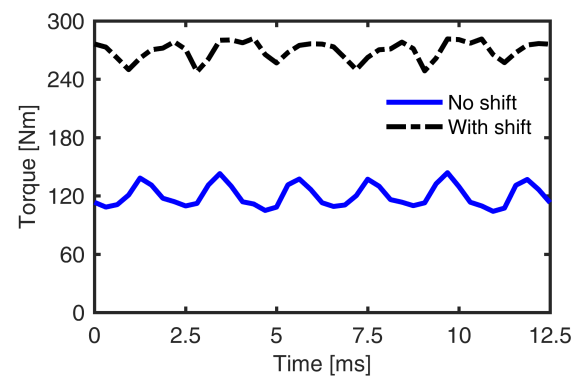

(c)

Figure 7. Open circuit emf for the 6/32 machine with 3 small auxiliary stator teeth per each large tooth with: (a) the two stators aligned, (b) stators circumferentially shifted from each other by $180^{\circ}$ electrical, and (c) instantaneous torque with and without the shifting. Shifting of the stators significantly increases the open circuit emf, and the torque.

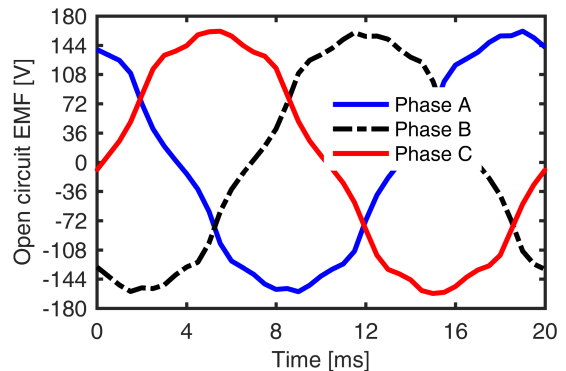

(a)

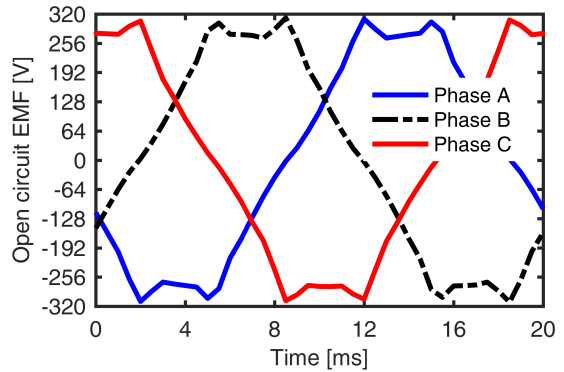

(b)

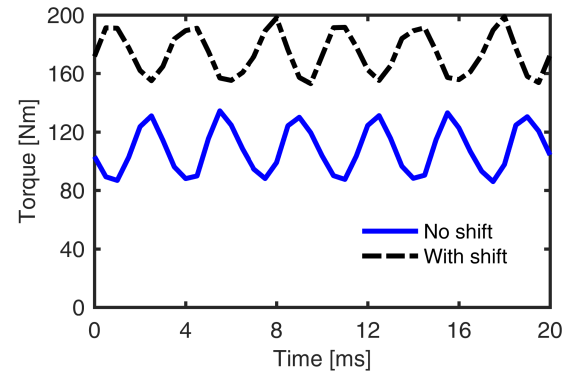

(c)

Figure 8. Open circuit emf for the $6 / 20$ machine with 2 small auxiliary stator teeth per each large tooth with: (a) the two stators aligned, (b) stators circumferentially shifted from each other by $180^{\circ}$ electrical, and (c) instantaneous torque with and without the shifting. Shifting of the stators increases the torque by only about $50 \%$, in contrast to the $6 / 32$ machine and the torque ripple is very high.

reduces. While there are many advantages due to stator shifting, it should not be forgotten that the introduced asymmetry may change the balance of axial forces of attraction between the two stators and the rotor with possible implications in terms of noise, vibrations, bearings and enclosure designs etc.

A special note is due for the relatively low power factor, which is often regarded as a typical natural limitation of Vernier type machines. A low power factor increases the voltampere rating of the inverter and results in higher cost for power electronics. While this maybe a concern, especially for high speed operation, it may not be a major issue for low-speed high-torque applications, in which case the relatively physical large size of the electric machine may be the dominant factor for the system cost.

An interesting application of the principle of shifting the two stators with respect to each other could be the functionality of an effective "Mechanical Field Weakening". In the constant torque region, the two stators may be shifted with respect to each other by one rotor pole pitch, at which maximum torque per ampere is obtained. With increasing speed, the circumferential shift between the stators could be modified, leading to a reduction in back emf and torque. The procedure may be used in conjunction with conventional electronic control schemes for field weakening in order to achieve a very wide constant power region.

\section{CONClusion}

This paper proposes a dual-stator single-rotor axial flux PM machine topology with a very high ratio of rotor poles to stator concentrated coils. Such machines can be derived from fractional slot concentrated winding PM synchronous motors by adding relatively large "dummy" notches to the stator tooth tips in order to create a special profile of the airgap surface and permeance and enhance a magnetic gearing effect.

An example three phase motor with 6 coils, each wound around a main tooth, would be combined in a conventional PM synchronous motor with a 4 pole or with an 8 pole rotor. In the special examples discussed in the paper for the proposed topology, a machine with 6 coils and main teeth and multiple auxiliary teeth can be combined with a rotor with as low as 20 poles and as high as 46 poles. For the spoke rotor topology considered in the design studies and fixed values of the main design variables, the high polarity naturally increases the flux concentration, which, in addition to the magnetic gearing effect, results in very high specific torque and makes the comparison with conventional designs irrelevant.

The reported design studies comprise the tabulation of possible main and auxiliary teeth and rotor pole combinations and the comparative performance including specific power output, goodness, efficiency, power factor, and torque ripple. It is shown that circumferentially shifting the two stators with 


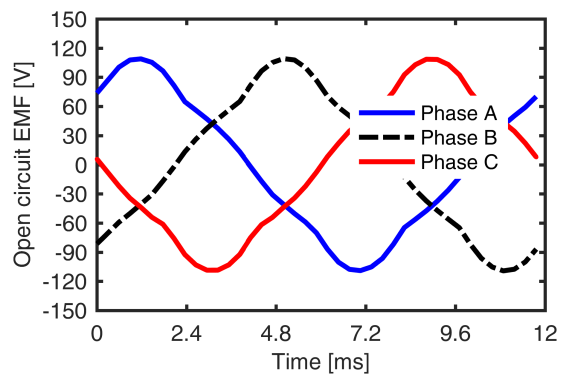

(a)

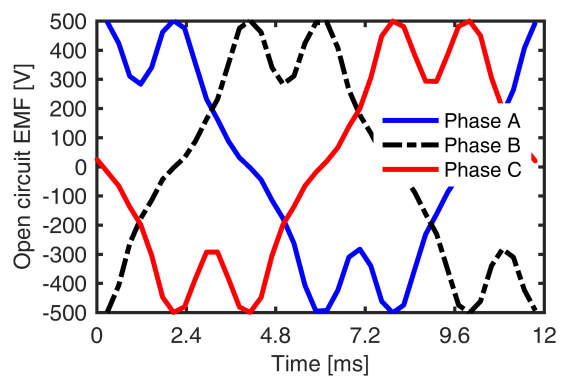

(b)

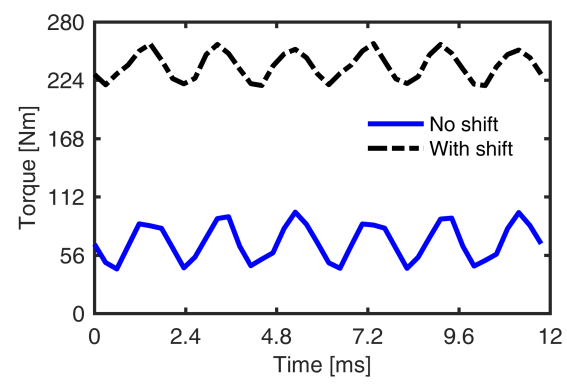

(c)

Figure 9. Open circuit emf for the 6/32 machine with 3 small auxiliary stator teeth per each large tooth with: (a) The two stators aligned, (b) stators circumferentially shifted from each other by $180^{\circ}$ electrical, and (c) instantaneous torque with and without the shifting. Without shifting of the stators, this machine has much lower torque than the other two studied topologies. Shifting of the stators increases the torque dramatically, making it perform better than the $6 / 20$ machine, and comparable to the $6 / 32$ machine.

respect to each other by one rotor pole pitch may significantly increase performance, for example by increasing the goodness by $50 \%$ and by reducing three times the torque ripple.

\section{REFERENCES}

[1] B. Mecrow and A. Jack, "A new high torque density permanent magnet machine configuration," in International Conference on Electric Machines, August 1990, pp. 1046-1052.

[2] H. Fujinaka, "Brush-less motor using Vernier structure," Patent US 7,064,468, Jun., 2006.

[3] F. Zhao, T. A. Lipo, and B. I. Kwon, "A novel dual-stator axialflux spoke-type permanent magnet Vernier machine for direct-drive applications," IEEE Transactions on Magnetics, vol. 50, no. 11, pp. 1-4, Nov 2014

[4] D. Li, R. Qu, and T. A. Lipo, "High-power-factor Vernier permanentmagnet machines," IEEE Transactions on Industry Applications, vol. 50, no. 6, pp. 3664-3674, Nov 2014.

[5] L. Xu, G. Liu, W. Zhao, X. Yang, and R. Cheng, "Hybrid stator design of fault-tolerant permanent-magnet Vernier machines for direct-drive applications," IEEE Transactions on Industrial Electronics, vol. 64, no. 1, pp. 179-190, Jan 2017.
[6] K. Okada, N. Niguchi, and K. Hirata, "Analysis of a Vernier motor with concentrated windings," IEEE Transactions on Magnetics, vol. 49, no. 5, pp. 2241-2244, May 2013.

[7] J. Li, K. T. Chau, J. Z. Jiang, C. Liu, and W. Li, "A new efficient permanent-magnet Vernier machine for wind power generation," IEEE Transactions on Magnetics, vol. 46, no. 6, pp. 1475-1478, June 2010.

[8] D. Li, R. Qu, J. Li, L. Xiao, L. Wu, and W. Xu, "Analysis of torque capability and quality in Vernier permanent-magnet machines," IEEE Transactions on Industry Applications, vol. 52, no. 1, pp. 125-135, Jan 2016.

[9] I. Boldea, L. Tutelea, and M. Topor, "Theoretical characterization of three phase flux reversal machine with rotor-PM flux concentration," in 2012 13th International Conference on Optimization of Electrical and Electronic Equipment (OPTIM), May 2012, pp. 472-476.

[10] J. Biela, M. Schweizer, S. Waffler, and J. W. Kolar, "SiC versus $\mathrm{Si}$; evaluation of potentials for performance improvement of inverter and DC DC converter systems by $\mathrm{SiC}$ power semiconductors," IEEE Transactions on Industrial Electronics, vol. 58, no. 7, pp. 2872-2882, July 2011.

[11] L. Wu, R. Qu, D. Li, and Y. Gao, "Influence of pole ratio and winding pole numbers on performance and optimal design parameters of surface permanent-magnet Vernier machines," IEEE Transactions on Industry Applications, vol. 51, no. 5, pp. 3707-3715, Sept 2015. 